\title{
Konfigurasi Routing BGP di Cisco Packet Tracer Akhmad Syarifudin \\ 175100012
}

Fakultas Komputer

Mahasiswa@institusi.ac.id

\begin{abstract}
BGP adalah sebuah protokol routing untuk pertukaran informasi antar autonomous system. autonomous system merupakan sebuah jaringan atau kelompok jaringan berada pada satu administrasi jaringan . BGP digunakan untuk pertukaran informasi routing untuk Internet dan merupakan protokol yang digunakan antar penyedia layanan Internet ( ISP ). Jaringan pelanggan, seperti perguruan tinggi dan perusahaan, biasanya menggunakan sebuah Interior Gateway Protocol (IGP ) seperti RIP atau OSPF untuk pertukaran informasi routing dalam jaringan mereka. Pelanggan terhubung ke ISP, dan ISP menggunakan BGP untuk bertukar pelanggan dan ISP rute . Ketika BGP digunakan antara sistem otonom ( AS ), protokol ini disebut sebagai BGP Eksternal ( EBGP ) . Jika penyedia layanan menggunakan BGP untuk bertukar rute dalam suatu AS, maka protokol disebut sebagai Interior BGP ( IBGP ).

Routing BGP (Border Gateway Protokol) merupakan salah satu jenis routing protokol yang digunakan untuk koneksi antar Autonomous System (AS), dan salah satu jenis routing protokol yang banyak digunakan oleh ISP besar atau pun kecil untuk perbaikan. Dan hasilnya device yang berbeda pada jaringan dapat saling berhubungan, dan konfigurasinya lebih mudah jika dibandingkan routing static atau lebih tepatnya kita dapat menghemat waktu lebih banyak.
\end{abstract}

Kata Kunci : Konfigurasi Routing BGP di Cisco Packet Tracer. 


\section{A. PENDAHULUAN}

Dalam dunia digital kita pasti sudah mengerti apa itu yang namanya internet. Bagaimana bisa kita bertukar data meskipun dengan jarak yang jauh, bahkan sangat jauh. Internet menggunakan gelombang elektromagnet sebagai transmisinya, sehingga dapat mencakup area yang sangan jauh, tetapi untuk menghubungkan ke internet ada aturan - aturan yang berlaku. Kita sebagai client awalnya harus terhubung terlebih dahulu ke penyedia atau provider, dan provider tersebut membeli suatu AUTONOMOUS SYSTEM NUMBER yang difungsikan sebagai nomor identitas provider tersebut. Tidak cuma ASN saja untuk dapat terhubung ke jaringan dunia tersebut, melainkan harus melakukan routing protokol BGP (Border Gateway Protokol) yang menghubungkan ke proviser lain di dunia.

Routing BGP (Border Gateway Protokol) merupakan salah satu jenis routing protokol yang digunakan untuk koneksi antar Autonomous System (AS), dan salah satu jenis routing protokol yang banyak digunakan oleh ISP besar atau pun kecil untuk perbaikan.

BGP termasuk kedalam kategori routing protokol jenis Exterior Gateway Protocol (EGP). Dengan adanya EGP, router dapat melakukan pertukaran rute dari dalam dan keluar jaringan lokal Autonomous System (AS). BGP mempunyai skalabilitas yang tinggi karena dapat melayani pertukaran routing pada beberapa organisasi besar. Oleh karena itu BGP dikenal dengan routing protokol yang sangat rumit dan kompleks.

\section{B. PEMBAHASAN / STUDI KASUS}

Border Gateway Protocol disingkat BGP adalah inti dari protokol routing internet. Protocol ini yang menjadi backbone dari jaringan internet dunia. BGP adalah protokol routing inti dari internet yg digunakan untuk melakukan pertukaran informasi routing antar jaringan. BGP memiliki tugas yang kurang lebih sama dengan divisi marketing dan promosi pada sebuah perusahaan. Tugas utama dari BGP adalah memberikan informasi tentang apa yang dimiliki oleh sebuah organisasi ke dunia di luar.

\section{Tujuan BGP}

adalah untuk memperkenalkan pada dunia luar alamat-alamat IP apa saja yang ada dalam jaringan tersebut. Setelah dikenal dari luar, server-server, perangkat jaringan, PC-PC dan perangkat komputer lainnya yang ada dalam jaringan tersebut juga dapat dijangkau dari dunia luar. Selain itu, informasi dari luar juga dikumpulkannya untuk 
keperluan organisasi tersebut berkomunikasi dengan dunia luar.

Dengan mengenal alamatalamat IP yang ada di jaringan lain, maka para pengguna dalam jaringan Anda juga dapat menjangkau jaringan mereka. Sehingga terbukalah halaman web Yahoo, search engine Google, toko buku Amazon, dan banyak lagi.

\section{Tahapan dan Pelaksanaan}

Buka aplikasi cisco paket tracer terlebih dahulu. Lalu buat topologi seperti berikut :

Untuk penjelasan lebih rinci nantikan update selanjutnya hehe, padahal lagi males Langsung ke bagian dimana kita akan simulasi kan bagaimana konfigurasi untuk routing protokol ini. kita coba dengan SSSD (skema sangat sangat sederhana)

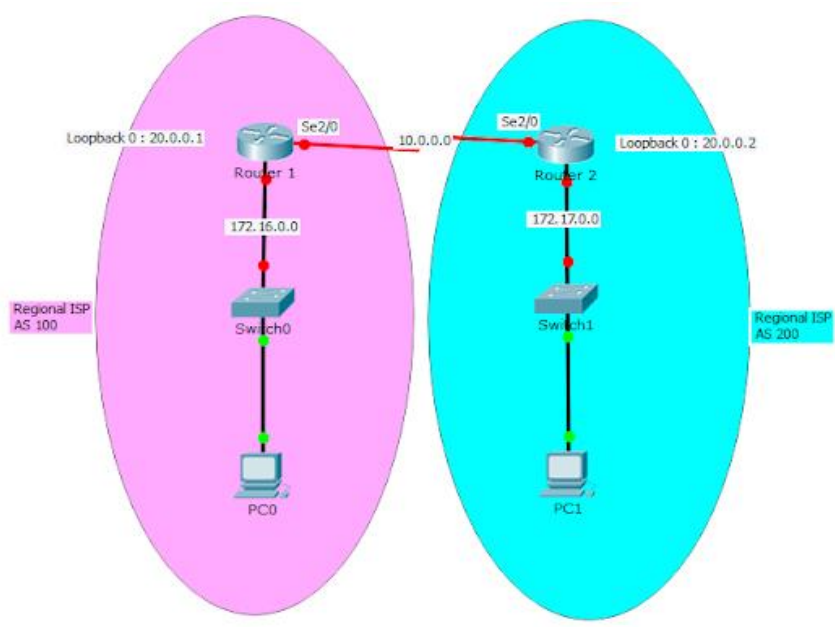

Pada skema ini tujuannya adalah menghubungkan dua network yang berbeda autonomous system agar bisa saling berkomunikasi. dan network yang kita advertise untuk skema BGP ini network dari interface loopback dari router.

Pertama, konfigurasi ip address dari masing masing interface pada setiap router, klik pada icon router dan masuk mode command line interface (CLI) :

\# Router 1

Router>enable

Router\#configure terminal

Router(config)\#hostname

Router-1

Router-1(config)\#interface serial $2 / 0$

Router-1(config-if)\#ip address 10.0.0.1 255.0.0.0

Router-1(config-if)\#no shutdown

Router-1(config-if)\#exit

Router-1(config)\#interface fastEthernet $0 / 0$

Router-1(config-if)\#ip address 172.16.1.1 255.255.0.0

Router-1(config-if)\#no shutdown

Router-1(config-if)\#exit Router-1(config)\#interface loopback 0 Router-1(config-if)\#ip address 20.0.0.1 255.0.0.0

Router-1(config-if)\#no shutdown

Router-1(config-if)\#exit

\# Router 2

Router>enable

Router\#configure terminal Router(config)\#hostname Router-2 
Router-2(config)\#interface serial $2 / 0$

Router-2(config-if)\#ip address 10.0.0.2 255.0.0.0

Router-2(config-if)\#clock rate 2000000

Router-2(config-if)\#no

shutdown

Router-2(config-if)\#exit

Router-2(config)\#interface

fastEthernet $0 / 0$

Router-2(config-if)\#ip address

172.17.1.1 255.255.0.0

Router-2(config-if)\#no

shutdown

Router-2(config-if)\#exit

Router-2(config)\#interface

loopback 0

Router-2(config-if)\#ip address 20.0.0.2 255.0.0.0

Router-2(config-if)\#no

shutdown

Router-2(config-if)\#exit

Setelah semua interface sudah terkonfigurasi,sekarang kita lakukan setting BGP

\# Router 1

Router-1(config)\#router bgp 100

Router-1(config-

router)\#neighbor

10.0.0.2

remote-as 200

Router-1(config-

router)\#network 20.0.0.0 mask 255.0.0.0

Router-1(configrouter)\#redistribute connected

Router-1(config-router)\#exit

Router-1(config)\#exit

Router-1\#copy running-config startup-config

Destination filename [startupconfig]?

Building configuration...
$[\mathrm{OK}]$

Router-1(config)\#router bgp

100 "Membuat sebuah

autonomous system BGP dengan no AS 100" Router-

1(config-router)\#neighbor

10.0.0.2 remote-as 200

"Mendaftarkan ip address dari interface router tetangga yang terhubung langsung dengan router yang AS nya diset 200" Router1(configrouter)\#network 20.0.0.0 mask 255.0.0.0 "Menetukan network address yang di advertise oleh BGP"

\# Router 2

Router-2(config)\#router bgp 200

Router-2(config-

router)\#neighbor

10.0.0.1

remote-as 100

\%BGP-5-ADJCHANGE:

neighbor 10.0.0.1 Up

Router-2(config-

router)\#network 20.0.0.2 mask

255.0.0.0

Router-2(config-

router)\#redistribute connected

Router-2(config-router)\#exit

Router-2(config)\#exit

Router-2\#copy running-config startup-config

Destination filename [startupconfig]?

Building configuration...

[OK]

\%BGP-5-ADJCHANGE:

neighbor 10.0.0.1 Up

"Maksudnya adalah router sudah bisa terkoneksi dengan router tetangga dengan BGP" 
Terakhir lakukan test koneksi dari PC0 ke PC1 atau sebaliknya

\section{Command Prompt}

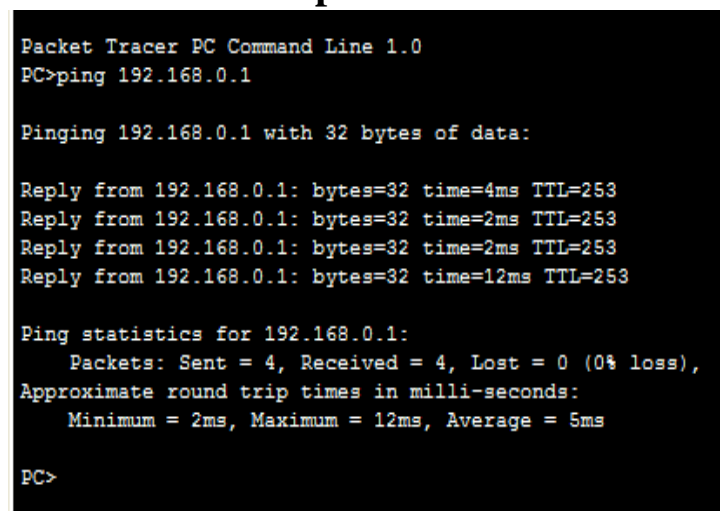

C. ID SECURITY

QWTD4452377-ASP-5244107

\section{KESIMPULAN}

Routing BGP (Border Gateway Protokol) merupakan salah satu jenis routing protokol yang digunakan untuk koneksi antar Autonomous System (AS), dan salah satu jenis routing protokol yang banyak digunakan oleh ISP besar atau pun kecil untuk perbaikan. Dan hasilnya device yang berbeda pada jaringan dapat saling berhubungan, dan konfigurasinya lebih mudah jika dibandingkan routing static atau lebih tepatnya kita dapat menghemat waktu lebih banyak.

\section{E. DISKUSI}

Saya bersama teman saya bernama Muhammad Arif, mendiskusikan tentang konfigurasi routing bgp di packet tracer ini dengan sangat baik. Hasil diskusi dari materi ini adalah bahwasannya bgp digunakan untuk pertukaran informasi routing untuk internet dan merupakan protokol yang digunakan antar penyedia layanan Internet (ISP). Dan hasilnya device yang berbeda pada jaringan dapat saling berhubungan, dan konfigurasinya lebih mudah jika dibandingkan routing static atau lebih tepatnya kita dapat menghemat waktu lebih banyak.

\section{F. REFERENCE}

O. M. Febriani and A. S. Putra, "Sistem Informasi Monitoring Inventori Barang Pada Balai Riset Standardisasi Industri Bandar Lampung," J. Inform., vol. 13, no. 1, pp. 90-98, 2014.

[2] A. S. Putra, "Paperplain: Execution Fundamental Create Application With Borland Delphi 7.0 University Of Mitra Indonesia," 2018.

[3] A. S. Putra, "2018 Artikel Struktur Data, Audit Dan Jaringan Komputer," 2018.

[4] A. S. Putra, "ALIAS MANAGER USED IN DATABASE DESKTOP STUDI CASE DB DEMOS."

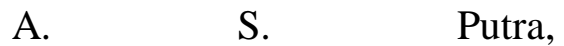
"COMPREHENSIVE SET OF PROFESSIONAL FOR DISTRIBUTE COMPUTING."

[6] A. S. Putra, "DATA ORIENTED RECOGNITION IN BORLAND DELPHI 7.0."

[7] A. S. Putra, "EMBARCADERO DELPHI XE 2 IN GPUPOWERED FIREMONKEY APPLICATION." 
[8] A. S. Putra, "HAK ATAS KEKAYAAN INTELEKTUAL DALAM DUNIA TEKNOLOGY BERBASIS REVOLUSI INDUSTRI 4.0."

[9] A. S. Putra, "IMPLEMENTASI PERATURAN PERUNDANGAN UU. NO 31 TAHUN 2000 TENTANG DESAIN INDUSTRI BERBASIS INFORMATION TECHNOLOGY."

[10] A. S. Putra, "IMPLEMENTATION OF PARADOX DBASE."

[11] A. S. Putra, "IMPLEMENTATION OF TRADE SECRET CASE STUDY SAMSUNG MOBILE PHONE."

[12] A. S. Putra, "IMPLEMENTATION PATENT FOR APPLICATION WEB BASED CASE STUDI WWW. PUBLIKLAMPUNG. COM."

[13] A. "IMPLEMENTATION SYSTEM FIRST TO INVENT IN DIGITALLY INDUSTRY."

[14] A. S. Putra, "MANUAL REPORT \& INTEGRATED DEVELOPMENT

ENVIRONMENT BORLAND DELPHI 7.0."

[15] A. S. Putra, "PATENT AS RELEVAN SUPPORT RESEARCH."

[16] A. S. Putra, "PATENT FOR RESEARCH STUDY CASE OF APPLE. Inc."

[17] A. S. Putra, "PATENT PROTECTION FOR APPLICATION INVENT."

[18] A. S. Putra, "QUICK REPORT
IN PROGRAMMING."'

[19] A. S. Putra, "REVIEW CIRCUIT LAYOUT COMPONENT

REQUIREMENT ON ASUS NOTEBOOK."

[20] A. S. Putra, "REVIEW TRADEMARK PATENT FOR INDUSTRIAL TECHNOLOGY BASED 4.0."

[21] A. S. Putra, "TOOLBAR COMPONENT PALLETTE IN OBJECT ORIENTED PROGRAMMING."

[22] A. S. Putra, "WORKING DIRECTORY SET FOR PARADOX 7."

[23] A. S. Putra, "ZQUERY CONNECTION

IMPLEMENTED

PROGRAMMING STUDI CASE PT. BANK BCA Tbk."

[24] A. S. Putra, D. R. Aryanti, and I. Hartati, "Metode SAW (Simple Additive Weighting) sebagai Sistem Pendukung Keputusan Guru Berprestasi (Studi Kasus: SMK Global Surya)," in Prosiding Seminar Nasional Darmajaya, 2018, vol. 1, no. 1, pp. 85-97.

[25] A. S. Putra and O. M. Febriani, "Knowledge Management Online Application in PDAM Lampung Province," in Prosiding International conference on Information Technology and Business (ICITB), 2018, pp. 181-187.

[26] A. S. Putra, O. M. Febriani, and B. Bachry, "Implementasi Genetic Fuzzy System Untuk Mengidentifikasi Hasil Curian Kendaraan Bermotor Di Polda 
Lampung," SIMADA (Jurnal Sist. Inf. dan Manaj. Basis Data), vol. 1, no. 1, pp. 21-30, 2018.

[27]A. S. Putra, H. Sukri, and K. Zuhri, "Sistem Monitoring Realtime Jaringan Irigasi Desa (JIDES) Dengan Konsep Jaringan Sensor Nirkabel," IJEIS (Indonesian J. Electron. Instrum. Syst., vol. 8, no. 2, pp. 221-232.

[28] D. P. Sari, O. M. Febriani, and A. S. Putra, "Perancangan Sistem Informasi SDM Berprestasi pada SD Global Surya," in Prosiding Seminar Nasional Darmajaya, 2018, vol. 1, no. 1, pp. 289-294. 